\title{
Calcium Phosphate Coatings Produced by Radiofrequency Magnetron Sputtering Method
}

\author{
E. N. Bolbasov ${ }^{1, \mathrm{a})}$, A. A. Zheravin ${ }^{2,3, \mathrm{~b})}$, I. A. Klimov ${ }^{2, \mathrm{c})}$, D. E. Kulbakin ${ }^{1,2, \mathrm{~d})}$, \\ V. M. Perelmuter ${ }^{2, \mathrm{e}}$, S. I. Tverdokhlebov ${ }^{1, \mathrm{f})}$, N. V. Cherdyntseva ${ }^{2, \mathrm{~g})}$, \\ and E. L. Choinzonov ${ }^{2, \mathrm{~h}}$ ) \\ ${ }^{1}$ Tomsk Polytechnic University, Tomsk, 634050 Russia \\ ${ }^{2}$ Tomsk Cancer Research Institute, Tomsk, Tomsk, 634050 Russia \\ ${ }^{3}$ Academician E.N. Meshalkin Novosibirsk State Research Institute of Circulation Pathology, Novosibirsk, Russia \\ a) ebolbasov@gmail.com \\ b) zheravin2010@yandex.ru \\ c)info@oncology.tomsk.ru \\ d) kulbakin_d@mail.ru \\ e) pvm的ngs.ru \\ f) Corresponding author: tverd@tpu.ru \\ g)nvch@oncology.tomsk.ru \\ h) choynzonov@oncology.tomsk.ru
}

\begin{abstract}
Calcium phosphate coatings on titanium implants surface, produced by radio frequency (RF) magnetron sputtering method with hydroxyapatite solid target were investigated. It was found that produced coatings are calcium deficient compared to stoichiometric hydroxyapatite. The surface of the coatings is highly rough at the nanoscale and highly elastic. In vivo experiments on rats revealed that titanium implants with the calcium phosphate coatings do not cause negative tissue reaction after 6 months incubation period.
\end{abstract}

\section{INTRODUCTION}

Due to such physical and mechanical features as high strength, relatively low elastic modulus, high corrosive resistance, and biocompatibility confirmed multiple times, titanium and its alloys are used in dental implant production, traumatology, orthopedics, maxillofacial surgery, etc. [1,2].

To increase titanium implants ability to integrate with bone tissue, the calcium phosphate coating is formed on their surface [3]. Among many calcium phosphate forming methods, the most commercially widespread ones are microarc oxidation [4] and plasma spray [5]. Calcium phosphate coatings produced employing these methods are characterized by high porosity and highly rough surface, which encourage adhesion and proliferation of stem cells and their further differentiation into osteoblasts [6]. One of the main disadvantages of such coatings is their low elasticity $[7,8]$. It limits their usage for implants functioning in significant flexural deformity environments such as titanium mesh, elastic intramedullary nails, etc.

A promising method of obtaining the calcium phosphate coatings with high adhesion to the implant and high elasticity is radio frequency (RF) magnetron sputtering. This method is applicable for producing calcium phosphate coatings on the surface of metallic, ceramic and polymeric implants [9, 10].

Widespread commercial use of the RF magnetron sputtering method for the production of calcium phosphate coatings is limited by the lack of research in the local impact of the coatings on the surrounding tissue.

The aim of our research is to study the local tissue reaction to model titanium implants with the calcium phosphate coatings produced by the RF magnetron sputtering method. 


\section{MATERIAL AND METHODS}

To form coatings by means of the RF magnetron sputtering method a hydroxyapatite solid target was used. When forming the coating, the following processing parameters were chosen: the frequency of $13.56 \mathrm{MHz}, \mathrm{pre}-$ pressure in the chamber of $5 \times 10^{-5} \mathrm{~Pa}$, operating pressure $\mathrm{Ar}$ of $3 \times 10^{-1} \mathrm{~Pa}$, volume high-frequency power of $20 \mathrm{~W} / \mathrm{cm}^{2}$.

The coatings were produced on the surface of the polished titanium discs sized $10 \times 2 \mathrm{~mm}$. Before the formation of the coatings, the discs were placed in an ultrasonic bath (Sapfir 5, Russia), and were step-by-step soaked in chloroform and in ethyl alcohol.

A research of coating morphology was carried out by means of a scanning electronic microscopy (SEM) (JCM$6000 \mathrm{Jeol}$, Japan). To conduct the research, a thin layer of gold was put on the surface of the coatings during $120 \mathrm{~s}$, using the magnetron sputtering system Smart Coater (Jeol, Japan). The coating morphological features (pore size, particle size) were defined by means of a program pack Image J 1.38 (National Institutes of Health, USA).

The surface of coatings was studied using atomic force microscopy (AFM) with high resolution (Solver-HV, NT-MDT, Russia). The measurements were performed in the air in ordinary conditions in semi-contact operation mode. The obtained images were analyzed using Gwyddion 2.25 software [11].

Coating elasticity $\xi$ was studied according to ISO 1519 recommendations: "Paints and varnishes—Bend test (cylindrical mandrel)" with the help of the Izgib tool (Gradient-Techno, Russia). In order to evaluate the elasticity the coatings were formed on a support sized $120 \times 35 \times 0.3 \mathrm{~mm}$. The coating elasticity value was chosen to be equal to the least diameter of a kernel when the bending around kernel does not cause the mechanical destruction or stripping of the coating.

The study of coating element composition was conducted via energy-dispersive analysis method (JCM-6000 Jeol, Japan). Estimation of semi-quantitative chemical constitution of the coating was conducted via method of 3 corrections for effective atomic number, absorption and fluorescence.

The study of local reaction of surrounding tissue to implantation of model implants with the developed coatings into muscular tissue was conducted in 24 wistar rats. Implantation was performed under general mixed anesthesia (relanium $0.5 \% 0.5-0.7 \mathrm{ml}$ intraperitoneally, ketamine $5 \% 0.3-0.4 \mathrm{ml}$ ). The procedures were performed with surgical tools and followed aseptic and antiseptics rules. 4 samples were implanted to each animal. The animals were pulled out of the experiment in 180 days. We gathered 3-5 mm thick tissues samples adjacent to the implants. The tissue samples were fixated in neutral formalin, dehydrated and soaked in paraffin wax to prepare histologic sections according to standard methods. The obtained thin $(6 \mu \mathrm{m})$ sections were dewaxed, stained with hematoxylin and eosin. To define a tissue type, the obtained sections were subjected to histological examination (MicroImaging, Carl Zeiss, Germany). All experiments were conducted subject to rules and principles of humane treatment of laboratory animals, stated in [12].

\section{RESULTS AND DISCUSSION}

The images of the surface of study samples are shown in the Fig. 1.

On the surface of polished support (Fig. 1a) we can observe multiple chaotically placed furrows, typical for metal surfaces, exposed to abrasive particle influence.

The surface of the calcium-phosphate coating produced by RF magnetron sputtering method is presented by insular-shaped particles sized $6.3 \pm 2.1 \mu \mathrm{m}$ longitudinally and $3.8 \pm 0.9 \mu \mathrm{m}$ laterally (Fig. 1b). Roughness parameter values for coating surface do not statistically differ from the value for a polished support. The high-resolution image of the surface (Fig. 1b, right top) shows that the coating is formed by spherulites with the average diameter of $200 \pm$ $70 \mathrm{~nm}$. Thus, the surfaces of calcium-phosphate coating produced by RF magnetron sputtering method are characterized by developed surface topology on the nanoscale due to the mechanism of their atomic growth. Calcium-phosphate coatings produced by RF magnetron sputtering method possess a low elasticity value due to high homogeneity on the "micro" scale and relatively low thickness.

Element composition of the coating produced via RF magnetron sputtering method is as follows: 26 mass. \% of Titanium (Ti), 3.6 mass. \%, of Calcium (Ca), 4.3 mass. \% of Phosphorus (P) and 66 mass. \% of Oxygen (O). The values of content proportion $\mathrm{Ca} / \mathrm{P}$ in coatings are also less than these values for stoichiometric hydroxyapatite. Value decrease effect of the $\mathrm{Ca} / \mathrm{P}$ proportion during formation of a coating via RF magnetron sputtering is apparently caused by kinematical processes during target sputtering, in which mass ratio of target atoms and operating gas, energy of ions striking the target and energy of atom bonds on the target surface [13] play a significant role. 

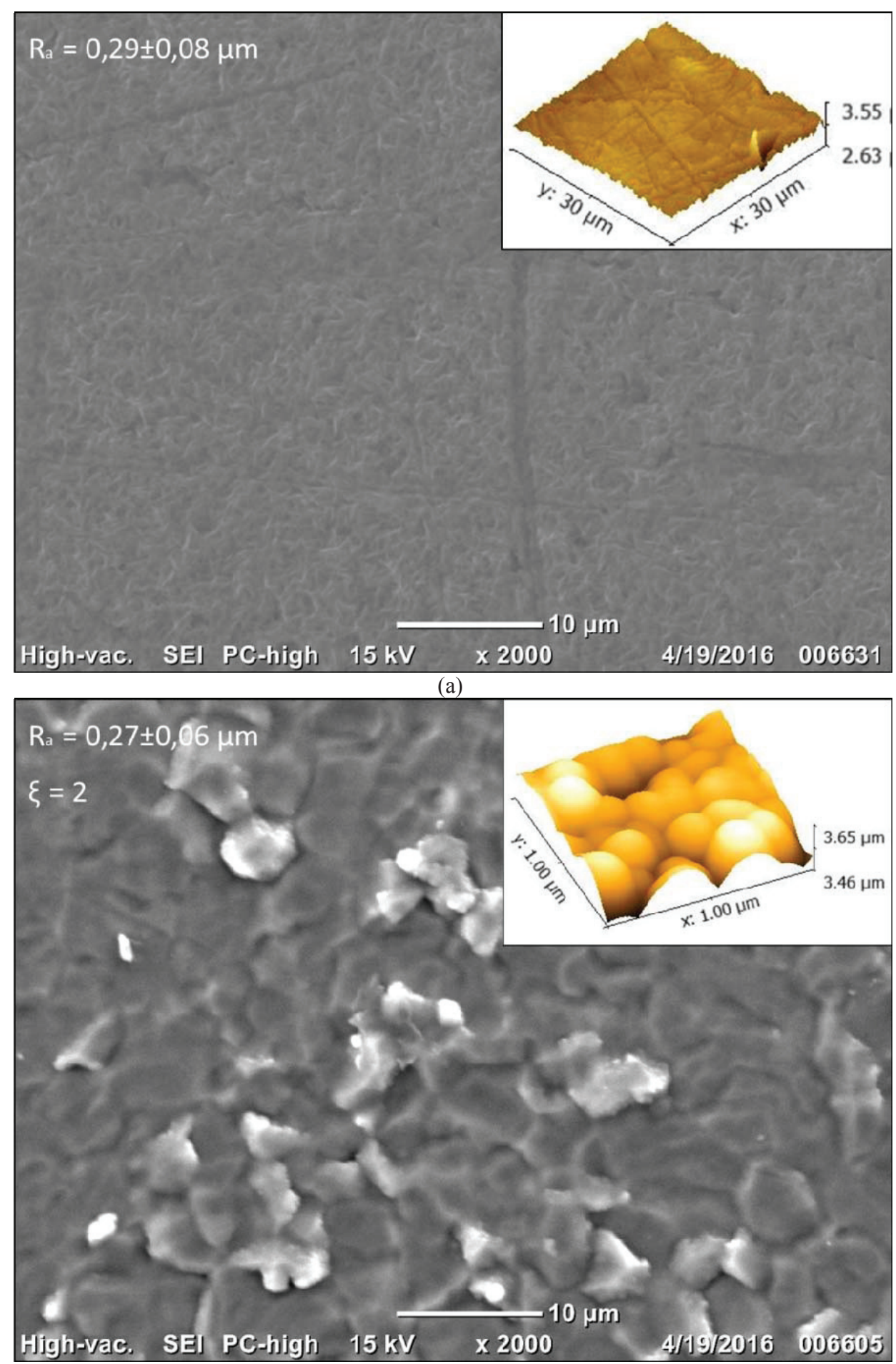

(b)

FIGURE 1. Images of surface of the samples: (a) polished support, (b) calcium-phosphate coating, produced by RFMS 
Since phosphorus atom mass is less than the one of calcium, the speed of phosphorus sputtering out of targets is higher and its quantity on the surface is higher as well. Phosphorus is also sputtered out of the target in the form of its combinations with oxygen $\left(\mathrm{PO}_{4}{ }^{3-}, \mathrm{PHO}^{+}\right)$, which possess bigger mass and their resputtering from the coating is hindered. The value decrease effect of the $\mathrm{Ca} / \mathrm{P}$ proportion was observed by the authors of the work [14].

\section{STUDY OF LOCAL REACTION OF SURROUNDING TISSUE TO IMPLANTATION INTO MUSCULAR TISSUE}

Visual examination of the implantation site has not shown any abnormal inclusions in the surrounding tissue. Moreover, no signs of suppuration, inflammation and infiltration of adjacent tissues were observed. The samples kept a stable position in the tissue and were surrounded by a transparent fibrous capsule.

The images of tissue histologic sections surrounding model titanium implants are shown in Fig. 2.

It can be seen that there are no signs of inflammation in the surrounding tissue after 6 months since titanium samples were implanted. The implant is surrounded by dense connective tissue (Figs. 2a, 2b). The titanium samples implantation with calcium phosphate coating also led to local inflammation reactions of the surrounding tissue on an implant. The implants are separated by a layer of connective tissue which is strongly adhered to muscle tissue (Figs. 2c, 2d).

The conducted study have not revealed any negative reactions to the placement of a model implant with calcium phosphate coating, produced by RF magnetron sputtering. Thus, it can be assumed that the obtained coating is biocompatible which allows us to proceed to the next step of testing the osteogenic properties of the coatings in in vivo systems.

The research determined that calcium phosphate coatings produced by RF magnetron sputtering are calcium deficient compared to stoichiometric hydroxyapatite, they have highly rough surface topology at the nanoscale and high elasticity. The obtained calcium phosphate coatings do not cause negative tissue reactions to implantation into muscular tissue for up to 6 months.

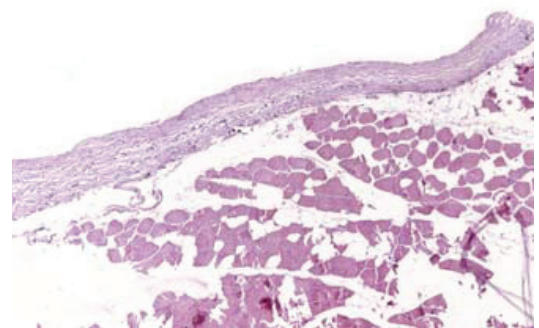

(a)

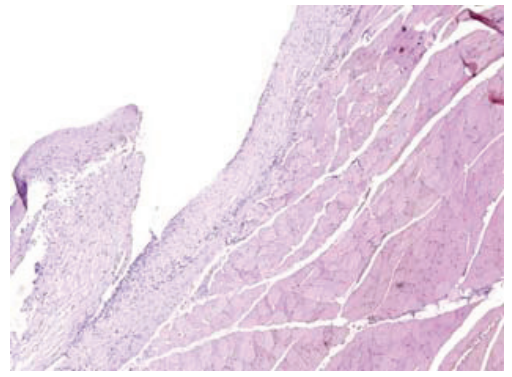

(c)

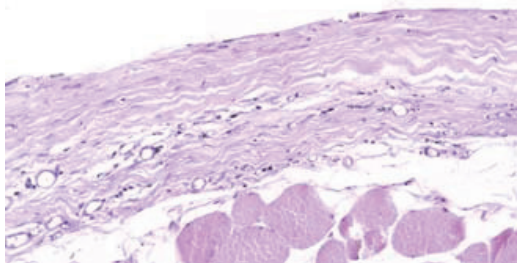

(b)

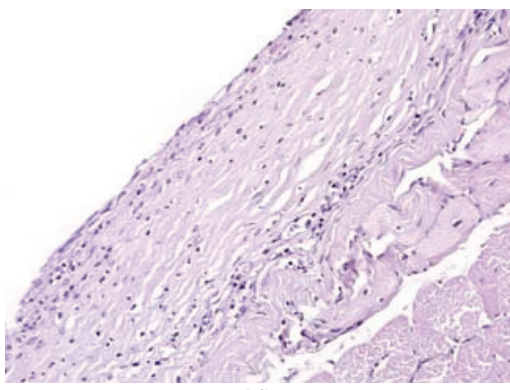

(d)

FIGURE 2. Tissue histologic sections surrounding model implants: titanium implants (a) $\times 50$, (b) $\times 200$, and titanium implants with calcium phosphate coating $(\mathrm{c}) \times 50$, (d) $\times 200$ 


\section{ACKNOWLEDGMENTS}

The research was financially supported by the Ministry of Education and Science of the Russian Federation, Federal Target Program (agreement No. 14.578.21.0031, unique identifier RFMEFI57814X0031).

The study reported in this article was conducted according to accepted ethical guidelines involving research in humans and/or animals and was approved by an appropriate institution or national research organization.

The study is compliant with the ethical standards as currently outlined in the Declaration of Helsinki.

All individual participants discussed in this study, or for whom any identifying information or image has been presented, have freely given their informed written consent for such information and/or image to be included in the published article.

\section{REFERENCES}

1. H. Matsuno, A. Yu. Eroshenko, V. A. Kukareko, A. V. Belyi, and V. A. Bataev, Biomaterials 22(11), 1253$1262(2001)$.

2. Y. P. Sharkeev, et al., Steel Transl. 42(8), 630-633 (2012).

3. S. R. Paital and N. B. Dahotre, Mater. Sci. Eng. R Rep. 66(1-3), 1-70 (2009).

4. O. P. Terleeva, Yu. P. Sharkeev, A. I. Slonova, I. V. Mironov, E. V. Legostaeva, I. A. Khlusov, E. Matykina, P. Skeldon, and G. E. Thompson, Surf. Coatings Technol. 205(6), 1723-1729 (2010).

5. S. W. Kweh, K. Khor, and P. Cheang, Biomaterials 21(12), 1223-1234 (2000).

6. R. Z. LeGeros, Chem. Rev. Am. Chem. Soc. 108(11), 4742-4753 (2008).

7. P. Cheang and K. A. Khor, Biomaterials 17(5), 537-544 (1996).

8. Y. C. Tsui, C. Doyle, and T. W. Clyne, Biomaterials 19(22), 2015-2029 (1998).

9. A. M. Aronov, V. F. Pichugin, E. V. Eshenko, M. A. Ryabtseva, R. A. Surmenev, S. I. Tverdokhlebov, and E. V. Shesterikov, Biomed. Eng. 42(3), 123-127 (2008).

10. S. I. Tverdokhlebov, E. N. Bolbasov, E. V. Shesterikov, L. V. Antonova, A. S. Golovkin, V. G. Matveeva, D. G. Petlin, and Y. G. Anissimov, Appl. Surf. Sci. 329, 32-39 (2015).

11. D. Nečas and P. Klapetek, Open Phys. 10(1), (2012).

12. C. G. Janet, R. W. Barbee, J. T. Bielitzki, L. A. Clayton, J. C. Donovan, C. F. M. Hendriksen, D. F. Kohn, N. S. Lipman, P. A. Locke, J. Melcher, F. W. Quimby, P. V. Turner, and G. A. Wood (National Academies Press, Washington DC, 2011).

13. P. Sigmund, Phys. Rev. 184(2), 383-416 (1969).

14. K. Ozeki, T. Yuhta, Y. Fukui, and H. Aoki, Surf. Coatings Technol. 160(1), 54-61 (2002). 